\title{
Pesquisa clínica no Japão: caminhos para aliviar cargas regulatórias desnecessárias
}

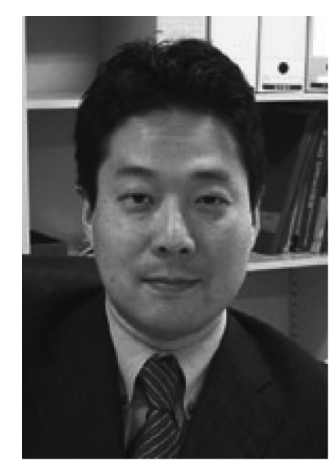

Koji Kawakami

Departamento de

Farmacoepidemiologia,

Graduate School of

Medicine and Public Health,

Kyoto University, Quioto,

Japão

kawakami-k@pbh.med.kyotou.ac.jp

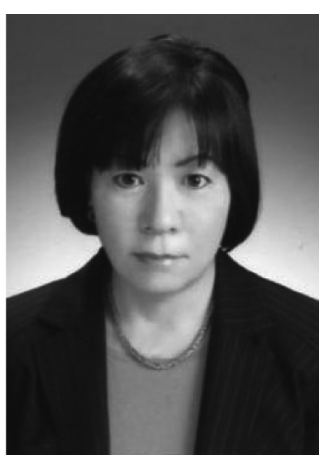

Hiroko Yamane

Graduate Institute for Policy Studies, Tóquio, Japão

hiroko-yamane@nifty.ne.jp

\section{Resumo}

Para a descoberta e desenvolvimento de medicamentos hoje, a sinergia entre ciência pura, pesquisa clínica e planejamento de testes clínicos é essencial. No Japão, a resposta a essa necessidade foi adiada. Este artigo identifica um dos gargalos no processo regulatório japonês. A pesquisa clínica sob responsabilidade dos pesquisadores da universidade e dos médicos não está integrada aos procedimentos de aprovação dos medicamentos japoneses. Portanto, seus esforços e dados de pesquisas são dissipados na longa e dispendiosa pesquisa biomédica, de natureza inerentemente imprevisível. Esforços colaborativos entre empresas e médicos/pesquisadores deveriam ser estimulados por meio de incentivos institucionais, integrando a universidade e a pesquisa clínica $a b$ initio ao processo regulatório. Para conseguir isso, seria necessário promover o intercâmbio comercial de informações de bancos de dados e, a curto prazo, o emprego de pesquisadores nos projetos que levam à aprovação regulatória.

\section{Palavras-chave}

Biotecnologia, biológicos, desenvolvimento de medicamentos, ciência regulatória, teste clínico

\section{Introdução}

Em todo o mundo, o advento de genômicos, genéticos e proteômicos colocou um desafio maciço para os pesquisadores das universidades, as empresas farmacêuticas e igualmente para as agências reguladoras. No que se refere à descoberta e ao desenvolvimento de medicamentos, a mudança de paradigma no final da década de 1990 foi radical. Uma série ampla de novas tecnologias e técnicas in-vitro para animais e seres humanos substituiu a tradicional manipulação química, exigindo não só investimentos mais sofisticados, mas também mais estudos científicos, pesquisa básica e biotecnologia. Para as empresas, um crescimento maciço de exigências regulatórias, tanto nos períodos pré-lançamento como pós dos produtos, resultou em mudanças significativas nos riscos e benefícios. Para as agências reguladoras, a necessidade de garantir medicamentos não-tóxicos, seguros e eficazes levou a adiamentos significativos do desenvolvimento de novos critérios para julgar se as invenções medicinais submetidas a análises eram de fato seguras e eficazes. Concomitantemente a essas dificuldades, os riscos de super-regulação inadequada às necessidades reais aumentaram.

Desde que essa mudança de paradigma ocorreu, o desenvolvimento dos medicamentos tornou-se estreitamente ligado com, e dependente do, avanço da ciência 
e da pesquisa básica. A nova área de pesquisa que surgiu desse processo de descobertas pode ser chamada "biofarmacêutica" e inclui medicamentos da medicina molecular contra doenças genéticas. Assim, os pesquisadores e as empresas foram induzidos a trabalhar em terrenos mais ou menos comuns.

Este artigo procura identificar gargalos na regulação japonesa e propõe caminhos para eliminar o que parecem ser sobreposições arcaicas. Ao fazer isso, tentamos explorar questões complexas, envolvidas no estímulo às invenções na área da pesquisa médica, enfrentadas pelas autoridades regulatórias, particularmente em países onde as universidades e as empresas comerciais tinham pouco em comum antes da introdução da área biofarmacêutica.

\section{Campos comuns: biológicos}

De acordo com a definição dada pelo Center for Biologics Evaluation and Research (CBER) [Centro de
Avaliação e Pesquisa de Biológicos] da U.S. Food and Drug Administration (FDA) ${ }^{1}$, biológicos são materiais derivados das "fontes vivas", tais como células/tecidos e genes de seres humanos, animais e/ou microorganismos. A maioria dos biológicos é produzida usando biotecnologia, inclusive a manipulação de genes.

Eles podem oferecer meios eficazes de tratar uma variedade de doenças e problemas de saúde que atualmente não têm outros tratamentos disponíveis. Exemplos desses tratamentos são terapia celular e genética, vacinas, dispositivos alergênicos como kits de testes de HIV, e xenotransplante.

No Japão, comparativamente aos Estados Unidos e ao Reino Unido, pesquisas básicas nesses campos da terapia celular e do tecido, dos substitutos de sangue, e da terapia genética tiveram relativo êxito, ao passo que o desenvolvimento de classes terapêuticas que utilizam as tecnologias mais estreitamente relacionadas à genética é deficiente, como mostra o Quadro 1.

\section{Quadro 1 - Comparação dos Biológicos em Desenvolvimento - Japão e Estados Unidos (e Reino Unido)}

\begin{tabular}{|c|c|c|}
\hline Biológicos & Japão & $\begin{array}{l}\text { Estados Unidos } \\
\text { (e Reino Unido) }\end{array}$ \\
\hline \multirow{3}{*}{ Terapia genética } & $\begin{array}{c}\text { Anges MG } \\
\text { Doença vascular HGF } \\
\text { (angiogênese) }\{\mathrm{P} 2 \text { nos Estados } \\
\text { Unidos, P3 no Japão }\}\end{array}$ & Introgen \\
\hline & Oncolys BioPharma & \\
\hline & $\begin{array}{c}\text { Telomelysin }{ }^{\circledR} \text { (hTERTp-Ad5, para } \\
\text { vários tumores sólidos }\{\text { P1 nos } \\
\text { Estados Unidos }\}\end{array}$ & $\begin{array}{l}\text { Adenovírus-p53 (câncer de } \\
\text { cabeça e pescoço) }\{\text { P3 }\end{array}$ \\
\hline \multirow[b]{2}{*}{ Vacinas contra câncer } & \multirow[b]{2}{*}{$\begin{array}{c}\text { Vacina Peptide - "Taillomade" } \\
\text { \{P1 no Japão }\}\end{array}$} & $\begin{array}{c}\text { Vical, Inc } \\
\text { Vacina de DNA contra melanoma } \\
\text { malígno (HLA-B7) }\{\mathrm{P} 2\}\end{array}$ \\
\hline & & $\begin{array}{c}\text { Cell Genesys } \\
\text { GM-CSF(GVAX) para o câncer } \\
\text { da próstata }\{\text { P3 }\}\end{array}$ \\
\hline Terapia celular \& do tecido & $\begin{array}{l}B C S, I n c \\
\text { Regeneração da pele por meio de } \\
\text { auto-enxerto }\{\text { pré-clinico }\}\end{array}$ & $\begin{array}{l}\text { Intercytex (Reino Unido) } \\
\text { Produto para tratar lesões tópicas } \\
\text { crônicas persistentes }\{\text { P3 }\}\end{array}$ \\
\hline Substitutos do sangue & $\begin{array}{l}\text { Oxygenix, Co., Ltd. } \\
\text { Eritrócitos artificiais (OXY-0301) } \\
\{\text { pré-clínico\} }\end{array}$ & \\
\hline \multirow[b]{2}{*}{ RNAi $^{1}$} & & $\begin{array}{l}\text { Alnylam Pharmaceuticals } \\
\text { Direct RNAiTM, ALN-RSV01 (vírus } \\
\text { sincicial respiratório) }\{\mathrm{P} 1\}\end{array}$ \\
\hline & & $\begin{array}{c}\text { Sirna Therapeutics, Inc. } \\
\text { Sima-027 (siRNA } 1 \text { para AMD²) } \\
\{\text { P2\} (adquirido pela Merck em } \\
\text { outubro de 2006) }\end{array}$ \\
\hline
\end{tabular}


As trilhas regulatórias japonesas, altamente complicadas em todas as áreas farmacêuticas, são ainda mais complicadas no que diz respeito aos produtos da biotecnologia derivados de células, genes e tecidos, que são muito rigorosamente regulados. Por exemplo, antes de submeter uma requisição de teste clínico a uma agência regulatória, o interessado deve primeiro solicitar à mesma agência uma análise relativa à química, à fabricação e ao controle $(\mathrm{CMC})^{2}$ do produto. Assim, a terapêutica da biotecnologia deve passar por múltiplos processos de análise antes de entrar no estágio de teste clínico.

A esperança que as indústrias japonesas depositaram no futuro da biotecnologia japonesa foi, durante um certo tempo, preponderante. Aproximadamente um bilhão de dólares foi investido na área, em 2004, para criar uma "mini-bolha". No entanto, as expectativas caíram dramaticamente porque não se conseguiu eficácia com o investimento. Parece que essa decepção veio da impressão de que mecanismos regulatórios e estrutura institucional não estão funcionando de maneira a favorecer o uso racional de recursos.

\section{Trilhas regulatórias no Japão}

O processo de descoberta, desenvolvimento, e obtenção de aprovações regulatórias para uma invenção medicinal envolve estágios "pré-clínicos" e "clínicos". O estágio pré-clínico consiste em pesquisa exploratória, com a perspectiva de identificar "candidatos" a medicamentos. Esses "candidatos" são, então, testados e desenvolvidos até que sejam obtidas informações suficientes através de estudos in-vitro e com animais. O estágio clínico requer uma série de estudos clínicos com seres humanos. O processo pode levar à aprovação regulatória, que se tornou cada vez mais rara. No contexto do estágio préclínico, pode ser difícil distinguir pesquisa exploratória e desenvolvimento, por um lado, e a realização de testes para obter aprovação regulatória, por outro.
Nesse processo em que ciência, medicina e indústria se misturam, uma das difíceis questões é quem conduz o processo de requisição de testes clínicos para se obter a aprovação dos medicamentos. Nos Estados Unidos, empresas, instituições acadêmicas, e companhias de capital de risco que investem em biotecnologia nas universidades são denominadas "patrocinadores", e todas elas podem submeter uma Investigational New Drug Application (IND) [Requisição de análise de novos medicamentos] à FDA. Sem exceção, estão sujeitas ao controle da FDA. Isso faz com que diferentes interessados, como pesquisadores, médicos e empresas farmacêuticas, tenham flexibilidade para desenvolver medicamentos.

No Japão, ao contrário, com a Pharmaceutical Affairs Law [Lei para Assuntos Farmacêuticos], os testes clínicos (em japonês, denominados "Shiken") somente podem ser "patrocinados" pelas empresas farmacêuticas. Esses testes, que devem ser realizados por médicos e pesquisadores, constituem uma categoria separada denominada "pesquisa clínica" de produtos terapêuticos não-aprovados, que é regulada também pela Medical Affairs Law [Lei para Assuntos Médicos]. Geralmente, a expressão "pesquisa clínica” é compreendida como "pesquisa orientada para o paciente", constituindo parte do tratamento médico. No entanto, no Japão, ela inclui fazer testes clínicos não só de medicamentos aprovados, com o objetivo de expandir seu uso, mas também de medicamentos não-aprovados, realizados apenas por médicos e somente em hospitais. A pesquisa clínica tem dado cada vez mais importância ao desenvolvimento de medicamentos biológicos e terapêuticos, de modo a melhorar a eficácia dos medicamentos existentes e ampliar seu campo terapêutico. Isto acontece, em parte, porque os recentes medicamentos biológicos e tratamentos à base destes têm como alvo, mais do que os sintomas, as genéticas individuais ou outras particularidades que causam as doenças em questão.

\section{Diagrama 1 - o papel da academia e das empresas farmacêuticas}

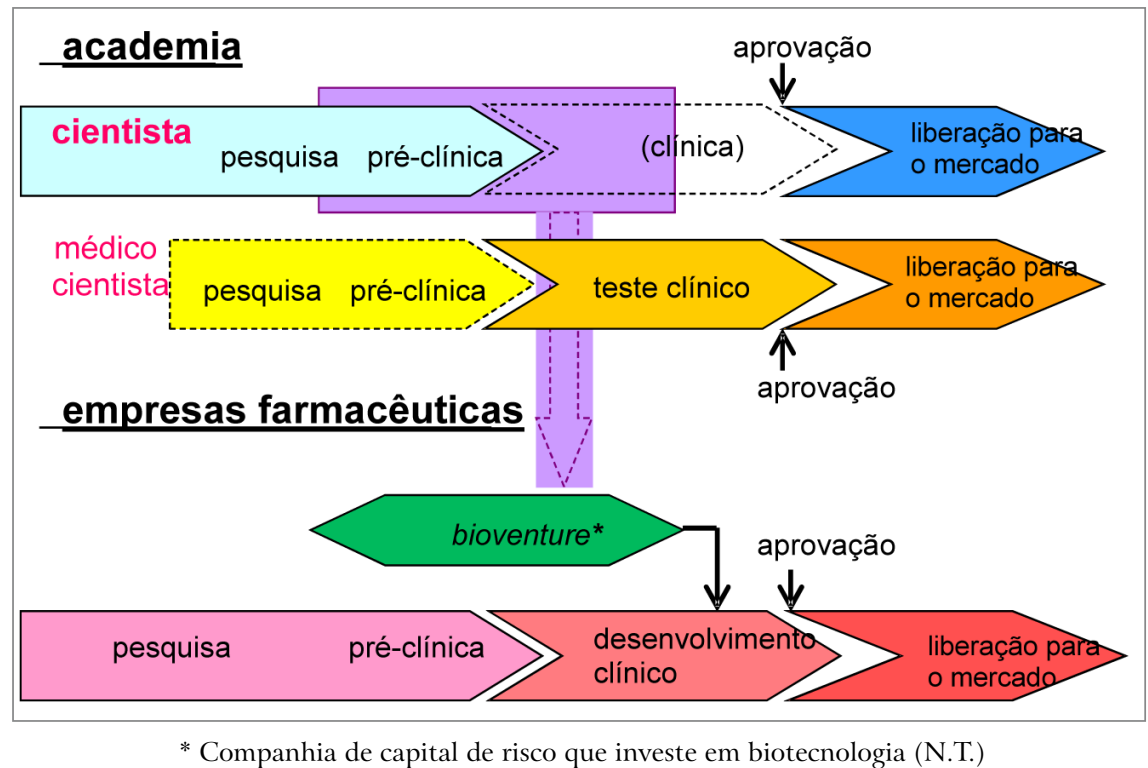


de medicamentos que constituem a Pharmaceuticals and Medical Devices Agency (PMDA) [Agência de Normas Farmacêuticas e Médicas]. A pesquisa clínica pode ser integrada ao processo "Shiken" conduzido pela indústria farmacêutica, mas isso requer que os pesquisadores e médicos decidam antecipadamente qual é o objetivo de suas pesquisas. Além disso, os dados clínicos obtidos com a pesquisa clínica inicial não podem ser usados na elaboração do protocolo "Shiken" para a aprovação de medicamentos.

Esse sistema de pesquisa clínica inteiramente separada do processo de aprovação de medicamentos apresenta dois tipos de ineficiência. Se a pesquisa clínica produzir resultados promissores para o desenvolvimento de medicamentos, depois de anos de trabalho, a equipe tem de voltar ao estágio inicial de testes clínicos para passar pelo processo "Shiken", como mostra o Diagrama 2. Em segundo lugar, os dois sistemas separados não têm um banco de dados com informações comuns para compartilharem.

Que rumo deveria seguir a reforma regulatória?

Antes de mais nada, sistemas de aprovação regulatória deveriam ser concebidos com base em um princípio que desse aos pesquisadores e médicos a opção de

\section{Diagrama 2 - trilhas dos testes clínicos no Japão}

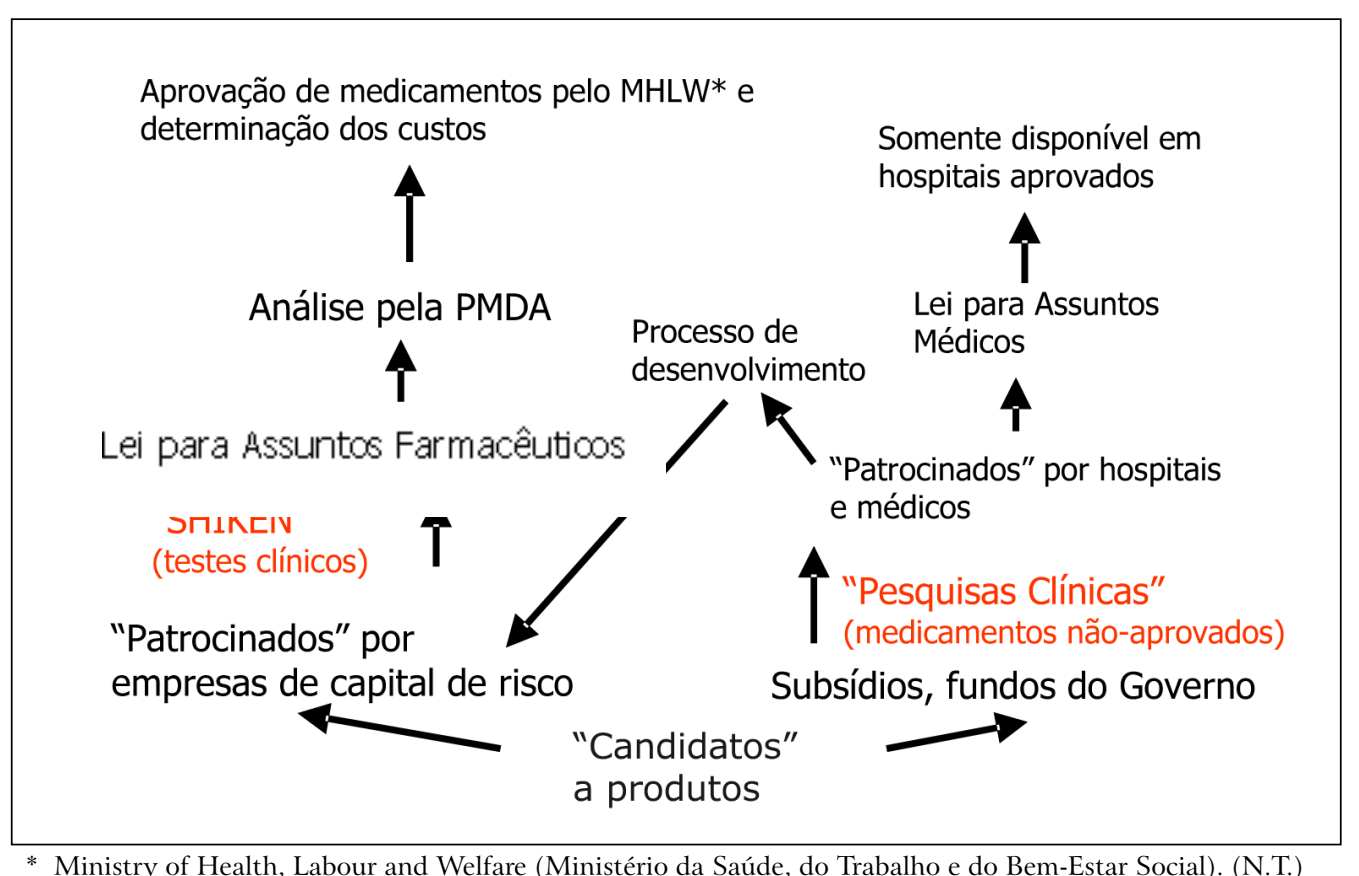

utilizar seus dados clínicos com propósitos de aprovação regulatória quando achassem apropriado, levando em conta a natureza longa e dispendiosa inerentemente imprevisível da pesquisa biomédica. Isso significa que qualquer rigidez relativa à admissão deve ser evitada. Em segundo lugar, esforços de colaboração entre empresas e pesquisadores/médicos devem ser estimulados por meio de incentivos institucionais. Exemplos desses incentivos incluem mecanismos para estimular o intercâmbio comercial de informações de bancos de dados e, a curto prazo, o envolvimento ou o emprego de pesquisadores em projetos que levem à aprovação regulatória.

Mais importante ainda é que as autoridades regulatórias devem estabelecer um critério uniforme e claro de aprovação. Esse último elemento é deficiente no Japão, causando uma dissipação significativa de informações, tempo e qualificações profissionais. Os que desenvolvem medicamentos japoneses (isto é, as empresas farmacêuticas) constantemente frustram-se, com toda razão, porque as normas de procedimento não são claras e explícitas o suficiente para explicarem o que é requerido. Além disso, não há nenhuma política sem restrições na agência regulatória para qualquer questão.

\section{Adendo}

Todo país tem diferentes tradições administrativas para estimular a ciência, a tecnologia e a pesquisa médica. Hoje, uma sinergia entre investigação científica pura, pesquisa clínica e organização de testes clínicos é essencial para a descoberta e o desenvolvimento de medicamentos. Interesses estabelecidos de cada instituição (e de cada pessoa) na estrutura administrativa anterior, assim como a luta política no terreno ideológico, tendem a ter impactos negativos enormes no avanço da ciência e da tecnologia. Todo país deve avaliar a eficácia de seus próprios sistemas administrativos e regulatórios relativa ao desenvolvimento de medicamentos de maneira colaborativa e objetiva. $\mathrm{O}$ principal objetivo das agências regulatórias de medicamentos é garantir não só a segurança e a eficácia de medicamentos e tratamentos terapêuticos, mas também que os dados pré-clinicos e clínicos cientificamente válidos possam ser aceitos por todas as agências regulatórias mundiais após a aprovação de testes clínicos multinacionais. Isto significa que pacotes de dados de "tamanho único" para segurança e eficácia devem ser padronizados no mais alto nível para qualquer estratégia séria de desenvolvimento de medicamentos. A ineficiência de regulações nacionais 
não baseadas na ciência ou na razão deve ser reconsiderada como obstáculo para um desenvolvimento sólido de medicamentos e tratamentos terapêuticos.

\section{Notas}

1. Órgão governamental dos Estados Unidos responsável pela regulação dos alimentos, medicamentos, cosméticos, biológicos, produtos derivados do sangue etc. (N.T.)

2. ARN interferente. (N.T.)

3. Small interfering RNA (pequena interferência com o ARN). (N.T.)

4. Age-related macular degeneration (degeneração da mácula relacionada à idade). (N.T.)

5. Chemistry, Manufacturing and Control - Química, Produção e Controle. (N.T.)

6. Shiken significa prova, teste, exame; por exemplo, o exame de proficiência em língua japonesa denomina-se
Nihongo Noryoku Shiken; no contexto deste artigo, trata-se do processo de requisição de testes clínicos, às autoridades regulatórias, para se obter a aprovação dos medicamentos. (N.T.)

\section{Referências bibliográficas}

SPRINGHAM, D. G.; MOSES, V.; CAPE, R.E. Biotechnology: the science and the business, 2.ed. Amsterdam: Harswood Academic Publishers, 1999.

Special report from the 3rd DIA multitrack workshop in Japan: Scientific review and clinical development of advanced therapeutics and biologics, Global Outsourcing Review, v.9, p.10-15, 2007.

KAWAKAMI, K.; PURI, R.K. Regulatory expectation during product development for tumor vaccines. Developments in Biologicals, v.116, p. 53-59, 2004.

\section{Sobre os autores}

\section{Koji Kawakami, M.D., Ph.D}

Professor e chefe do Departamento de Farmacoepidemiologia da Escola de Graduação em Medicina e Saúde Pública da Kyoto University, em Kyoto no Japão e professor adjunto da National University of Singapore (NUS) em Singapore além de membro sênior de medicina do Japan Science and Technology Agency (JST-CRDS). Depois de sua residência em cirurgia de cabeça e pescoço no Japão, juntou-se ao Center of Biologics Evaluation and Research (CBER) do United States Food and Drug Administration (FDA) e conduziu diversos projetos de pesquisa em imunobiologia citocina, terapia de genes e terapia de câncer localizado. Além disso, é avaliador de regulação de produtos especializado em vacinas contra tumores e terapia genética no tratamento do câncer na FDA, e revisor das submissões de estudos de novos medicamentos feitas por indústrias e institutos acadêmicos americanos. Atualmente, está conduzindo projetos de pesquisa focado em políticas de medicamento de saúde, farmacoepidemiologia e terapias de câncer localizado.

\section{Hiroko Yamane}

Professora de Direito no National Graduate Institute for Policy Studies (GRIPS) em Tóquio no Japão. O governo japonês criou a GRIPS em 1997, com o objetivo de treinar oficiais do governo tanto de for a quanto do Japão, através de programas de mestrado e doutorado em Economia e Políticas Públicas (http://www.grips.ac.jp). Especializada em Competição, Direitos de Propriedade Intelectual e Direito do Comércio, suas áreas de estudo incluem competição e regularização, licenciamento e também vários assuntos relacionados o Tratado Sobre Direitos de Propriedade Intelectual Relacionado ao Comércio Internacional (TRIPS), tais como pesquisa e desenvolvimento, saúde pública, e diversidade biológica. Entre 2004 e 2006, foi membro da Comissão Internacional de Propriedade Intelectual, Inovação e Saúde Pública da Organização Mundial de Saúde. 